\title{
Corrigendum: Multi-Source Pathways of T Follicular Helper Cell Differentiation
}

\author{
Xiaoxue $\mathrm{Ma}^{1,2,3^{*}}$, Shingo Nakayamada ${ }^{4 \dagger}$ and Jun Wang ${ }^{2,3}$ \\ 1 Department of Pediatrics, The First Hospital of China Medical University, Shenyang, China, ${ }^{2}$ Department of Microbiology \& \\ Immunology and Pediatrics, Dalhousie University, Halifax, NS, Canada, ${ }^{3}$ Canadian Center for Vaccinology, IWK Health \\ Centre, Halifax, NS, Canada, ${ }^{4}$ First Department of Internal Medicine, School of Medicine, University of Occupational and \\ Environmental Health, Japan, Kitakyushu, Japan
}

\section{OPEN ACCESS}

Approved by:

Frontiers Editorial Office,

Frontiers Media SA, Switzerland

*Correspondence:

Xiaoxue Ma

snow1999521@126.com

${ }^{\dagger}$ These authors have contributed

equally to this work

Specialty section:

This article was submitted to

$T$ Cell Biology,

a section of the journal

Frontiers in Immunology

Received: 04 April 2021 Accepted: 08 April 2021

Published: 07 May 2021

Citation:

Ma X, Nakayamada S and Wang J (2021) Corrigendum: Multi-Source

Pathways of T Follicular Helper

Cell Differentiation.

Front. Immunol. 12:690815. doi: 10.3389/fimmu.2021.690815
Keywords: T follicular helper cell, cytokine, signal transducer and activator of transcription, pathway, differentiation

\section{A Corrigendum on}

Multi-Source Pathways of T Follicular Helper Cell Differentiation

By Ma X and Nakayamada S (2021). Front. Immunol. 12:621105. doi: 10.3389/fimmu.2021.621105

In the original article, we neglected to include the funder Canadian Institutes of Health Research, 201803PJT-159700 to JW.

In the original article, there was an error in the affiliations for Xiaoxue Ma. As well as having affiliations 1 and 2, XM should also have Canadian Center for Vaccinology, IWK Health Centre, Halifax, NS, Canada.

In the original article, Jun Wang was not included as an author. The corrected Author Contributions Statement appears below.

$\mathrm{XM}$ and SN created the research concept, designed and wrote the manuscript. JW was involved in the modification of the manuscript. All authors contributed to the article and approved the submitted version.

The authors apologize for these errors and state that this does not change the scientific conclusions of the article in any way. The original article has been updated.

Copyright (c) $2021 \mathrm{Ma}$, Nakayamada and Wang. This is an open-access article distributed under the terms of the Creative Commons Attribution License (CC BY). The use, distribution or reproduction in other forums is permitted, provided the original author(s) and the copyright owner(s) are credited and that the original publication in this journal is cited, in accordance with accepted academic practice. No use, distribution or reproduction is permitted which does not comply with these terms. 